\title{
Differential Gene Expression Among Genotypes of the Genus Saccharum Contrasting in Biomass Production ${ }^{+}$
}

\author{
Fernando Henrique Correr ${ }^{1}$, Guilherme Kenichi Hosaka ${ }^{1}$, Isabella Barros Valadão ${ }^{2}$, \\ Thiago Willian Almeida Balsalobre ${ }^{2}$, Monalisa Sampaio Carneiro ${ }^{2}$ \\ and Gabriel Rodrigues Alves Margarido 1,* \\ 1 Department of Genetics, Luiz de Queiroz College of Agriculture, University of São Paulo, \\ Piracicaba 13418-900, Brazil; fernando_correr@usp.br (F.H.C.); ghosaka8@usp.br (G.K.H.) \\ 2 Department of Biotechnology and Plant and Animal Production, Center for Agricultural Sciences, \\ Federal University of São Carlos, Araras 13600-970, Brazil; isabellavaladao@gmail.com (I.B.V.); \\ thiagobalsalobre@gmail.com (T.W.A.B.); monalisa@ufscar.br (M.S.C.) \\ * Correspondence: gramarga@usp.br \\ + Presented at the third International Tropical Agriculture Conference (TROPAG 2019), Brisbane, Australia, \\ 11-13 November 2019.
}

Published: 30 December 2019

\begin{abstract}
The development of biomass crops aims to meet industrial yield demands to become a profitable and sustainable activity. Achieving these goals in an energy crop such as sugarcane relies on breeding for sucrose accumulation, fiber content and tillering capacity. Sucrose storage depends on transport from leaves to culms driven by enzymes involved in sucrose synthesis and hydrolysis. High biomass genotypes often use photosynthesis products to produce lignocellulosic compounds to form the cell wall. To expand the understanding of the pathways related to these traits, we evaluated gene expression of two groups of genotypes contrasting in biomass yield, as well as testing for differences among members within the same group. First visible dewlap leaves were collected from six genotypes of each group to perform RNA-Seq. We found evidence that both groups differ with regard to genomic stress caused by polyploidy, as indicated by the enrichment of genes involved in transposition activity and defense response processes. Although carbon assimilation terms were not enriched, genes annotated with such terms were co-expressed with those coding for members of hormonal pathways. Sucrose phosphate synthase and hydrolytic enzymes coding genes were upregulated in leaves of sucrose-accumulating genotypes, as genes coding for enzymes involved in the biosynthesis of lignin. Compared to other high biomass accessions, the hybrid US85-1008 presented upregulation of photosynthesis-related genes probably due to its sink demand to store sugar in culms. This study expands the knowledge of gene expression in sugarcane leaves, revealing differences between and within phenotypically distinct groups.
\end{abstract}

Keywords: sugarcane; fiber; sucrose; RNA-Seq; functional genomics 
Funding: GRAM received a research grant, process 2015/22993-7, Fundação de Amparo à Pesquisa do Estado de São Paulo (FAPESP).

Conflicts of Interest: The authors declare no conflict of interest

(c) 2019 by the authors. Licensee MDPI, Basel, Switzerland. This article is an open access article distributed under the terms and conditions of the Creative Commons Attribution (CC BY) license (http://creativecommons.org/licenses/by/4.0/). 